\title{
A EDUCAÇÃO COMPARADA COMO PERSPECTIVA TEÓRICA EM ESTUDOS CURRICULARES NA EDUCAÇÃO MATEMÁTICA
}

\section{THE COMPARATIVE EDUCATION AS THEORETICAL PERSPECTIVE IN CURRICULUM STUDIES IN MATHEMATICS EDUCATION}

\author{
Harryson Júnio Lessa Gonçalves \\ Universidade Estadual Paulista, harryson@bio.feis.unesp.br \\ Célia Maria Carolino Pires \\ Universidade Cruzeiro do Sul, ccarolinopires@gmail.com
}

\begin{abstract}
Resumo
O presente artigo visa a discutir preceitos que permearam o desenvolvimento do projeto "Pesquisas comparativas sobre organização e desenvolvimento curricular na área de Educação Matemática, em países da América Latina", defendendo tal base teórica no âmbito da Educação Matemática. Para tanto, são debatidos aspectos conceituais e epistemológicos que nortearam a construção do referido projeto de pesquisa, bem como a proposição da diversidade cultural como norteadora de estudos de currículos de Matemática, tomando assim o pós-colonialismo como pressuposto teórico.
\end{abstract}

Palavras-chave: Educação Comparada, Currículos de Matemática, Investigações Curriculares, Diversidade Cultural.

\begin{abstract}
This article aims to discuss assumptions that permeated the development of the project "Comparative research on organization and curriculum development in mathematics education in Latin America," defending the theoretical basis in the context of mathematics education. Therefore, they are discussed conceptual and epistemological aspects that guided the construction of the said project, as well as the proposition of cultural diversity as a guiding curriculum studies in Mathematics, so taking post-colonialism as a theoretical assumption.
\end{abstract}

Keywords: Comparative Education, Curriculum Mathematics, Research in Mathematics Education, Curriculum Research. 


\section{Introdução}

A Educação Comparada não se reduz a recortes descontextualizados de países e suas simplificadas comparações, mas sim a investigações que analisam nações e culturas diversas a partir dos seus condicionantes sociais, econômicos, culturais, políticos e educacionais visando a compreender algumas interfaces que permeiam tais condicionantes. Desse modo, podemos caracterizá-la, a partir de Kazamias (2012), não como uma ciência social associada à predição ou orientada à formulação de políticas ou de aplicação prática, mas como uma episteme explicativa que busca compreender e interpretar a forma como os sistemas educacionais se desenvolveram.

Nesse sentido, a Educação Comparada pode ser compreendida como análises a serem realizadas entre sistemas educacionais de países diferentes e/ou, ainda, no contexto de uma mesma nação com condicionantes diversos, por exemplo, em regiões, estados e cidades - principalmente, em países como o Brasil que possui dimensões continentais (PIRES; GONÇALVES, 2015).

Por conseguinte, conforme apontamos em trabalho anterior (PIRES; GONÇALVES, 2015), investigações substanciadas na Educação Comparada podem surgir como campo profícuo no âmbito da Educação Matemática:

- Transferência educacional - utilização da consciência de modelos, políticas e práticas de um sistema educacional em outro (PHILLIPS, 2012);

- Organização e desenvolvimento curricular em Matemática - planificações e implementações curriculares, conteúdos matemáticos, currículo em ação, relações de professores que ensinam Matemática com materiais curriculares, avaliações curriculares, inovações curriculares;

- Formação e desenvolvimento profissional de professores que ensinam Matemática;

- Impactos de teorias da Educação Matemática no ensino de Matemática; história da Educação Matemática em diferentes países;

- Etnomatemática e Diversidade Cultural em Educação Matemática. 
Para tanto, o presente artigo visa a discutir pressupostos conceituais e epistemológicos que permearam o desenvolvimento do projeto "Pesquisas comparativas sobre organização e desenvolvimento curricular na área de Educação Matemática, em países da América Latina”, desenvolvido no âmbito da Pontifícia Universidade Católica de São Paulo (PUC/SP), defendendo, assim, a Educação Comparada como uma das perspectivas teóricas para guiar investigações curriculares no âmbito da Educação Matemática. Para tanto, as questões do presente artigo serão consubstanciadas na experiência constituída a partir do referido projeto de pesquisa.

\section{O projeto de pesquisa}

No Brasil, tal integração latino-americana apresenta-se como preceito na Constituição Federal previsto no parágrafo único do seu artigo 4. o: "a República Federativa do Brasil buscará a integração econômica, política, social e cultural dos povos da América Latina, visando à formação de uma comunidade latino-americana de nações”. A partir de tal preceito o Brasil tem tomado algumas ações para fortalecer a integração. Na educação, por exemplo, temos a obrigatoriedade do ensino de espanhol na Educação Básica e a criação de uma universidade pública destinada a contribuir com tal integração Universidade Federal da Integração Latino-Americana (Unila). Pressupomos que, no âmbito das políticas curriculares, as ações são ainda incipientes no tocante ao efetivo cumprimento de tal preceito, visto o distanciamento natural que o Brasil enfrenta dos demais países latinos em função de seu processo de colonização (NEWCOMB, 2012).

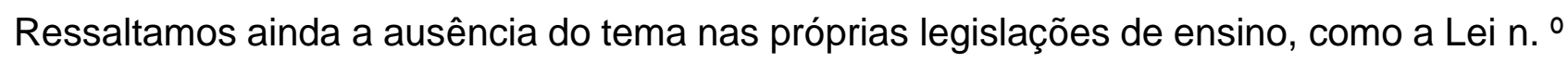
9.394/1996 (Lei de Diretrizes e Bases da Educação Nacional - LDB) e a Lei n.ำ13.005/2014 (Plano Nacional da Educação - PNE).

A comunidade internacional de educadores matemáticos tem se articulado com intuito de se consolidar como área de conhecimento e garantir um ensino de Matemática de melhor qualidade, conforme apontamos em trabalho anterior (PIRES; GONÇALVES, 2015). Tal integração viabiliza-se, principalmente, por programas de intercâmbios acadêmicos e científicos entre pesquisadores e estudantes (graduação e pós-graduação) promovidos por diversas agências nacionais e internacionais de fomentos. Outro exemplo de tal integração entre educadores matemáticos latino-americanos é a Federação Iberoamericana de Sociedades de Educação Matemática (Fisem), criada em 2003, que congrega 
diversas sociedades. ${ }^{1}$ A Fisem mantém uma revista de divulgação científica, a Unión, e é responsável pela organização do Congreso Iberoamericano de Educación Matemática (Cibem). Outros eventos também mobilizam a comunidade, entre eles a Conferencia Interamericana de Educación Matemática (Ciaem), a Reunião de Didática da Matemática do Cone Sul e a Reunião Latino-Americana de Matemática Educativa (Relme).

Pires (2013) afirma que estudos revelam que, embora o acesso à educação em todos os níveis tenha crescido substancialmente nos últimos anos com o aumento das taxas de alfabetização, a meta da Declaração Mundial de Educação para Todos (ORGANIZAÇÃO DAS NAÇÕES UNIDAS PARA A EDUCAÇÃO, A CIÊNCIA E A CULTURA, 1990), estabelecida nos anos 1990, é ainda um sonho remoto em razão das desigualdades sociais e econômicas que assolam os países latino-americanos. Ainda em Pires (2013), documentos mostram que os sistemas educacionais na América Latina abriram um leque mais amplo para a participação de atores, tais como organizações não governamentais (ONG) e as associações de pais e da sociedade civil, com base em um consenso comum de que a educação é uma prioridade nacional e regional. Apesar disso, o financiamento da Educação cresce muito lentamente e a utilização dos fundos disponíveis é ainda insuficiente. A distribuição dos serviços educacionais, em termos de eficiência e qualidade, é bastante injusta. Ademais, há uma ausência de mecanismos eficazes para que a sociedade civil venha a contribuir para a formulação de políticas na área da educação, bem como permanecem muito restritas a disponibilidade e a utilização das tecnologias de informação e comunicação. Não obstante os problemas, a América Latina manteve o ritmo da tendência global de crescente acesso ao ensino básico e ao ensino superior, na última década.

Em meio a esses avanços e desafios, Pires (2013) considerou importante para a comunidade de Educação Matemática das diversas nações refletir a respeito dessas questões e idealizou, em 2009, o projeto "Pesquisas comparativas sobre organização e desenvolvimento curricular na área de Educação Matemática, em países da América Latina”, desenvolvido no âmbito da Pontifícia Universidade Católica de São Paulo (PUC/SP). O projeto surge apoiado no grupo de pesquisa "Organização e Desenvolvimento

\footnotetext{
1 Sociedad Argentina de Educación Matemática (Soarem); Sociedade Brasileira de Educação Matemática (SBEM), Sociedad Chilena de Educación Matemática (Sochiem); Federación Española de Sociedades de Profesores de Matemáticas (FESPM); Asociación Nacional de Profesores de Matemáticas (ANPM, do México); Asociación Mexicana de Investigadores del Uso de Tecnología en Educación Matemática (Amiutem); Sociedad Peruana de Educación Matemática (Sopemat); Associação de Professores de Matemática (APM/Portugal); Sociedad de Educación Matemática de Uruguay (Semur); Sociedad Boliviana de Educación Matemática (SOBEDM); Asociación Venezolana de Educación Matemática (Asovemat); Comité de Educación Matemática de Paraguay (Cempa); Sociedad Ecuatoriana de Matemáticas (Sedem); e a Asociación Colombiana de Educación Matemática (Asocolme).
} 
Curricular em Matemática e Formação de Professores", 2 o qual foi constituído em 2000 e conta com a colaboração de 24 pesquisadores vinculados aos seus diversos projetos (tabela 1). O grupo apresenta uma expressiva produção científica (dissertações e teses) vinculada ao Programa de Estudos Pós-Graduados em Educação Matemática da PUC/SP (conforme tabela 1).

Tabela 1: Projetos de Pesquisa do Grupo "Desenvolvimento Curricular em Matemática e Formação de Professores em Matemática” (dissertações e teses - concluídas e em andamento)

\begin{tabular}{|c|c|c|c|c|c|}
\hline Projeto de Pesquisa & Período & DO & MA & MP & $\mathbf{T}$ \\
\hline $\begin{array}{l}\text { Inovações curriculares nos Ensinos Fundamental e } \\
\text { Médio }\end{array}$ & $\begin{array}{l}2000 \\
2008\end{array}$ & 1 & 9 & 11 & 21 \\
\hline Formação de professores de Matemática & $\begin{array}{l}2000 \\
2011\end{array}$ & 2 & 9 & 7 & 18 \\
\hline $\begin{array}{l}\text { Construção de trajetórias hipotéticas de } \\
\text { aprendizagem e implementação de inovações } \\
\text { curriculares em Matemática no Ensino Médio }\end{array}$ & $\begin{array}{l}2007 \\
2011\end{array}$ & 6 & 2 & 14 & 22 \\
\hline $\begin{array}{l}\text { O currículo de Matemática na Educação de jovens e } \\
\text { adultos: dos intervenientes à prática em sala de aula }\end{array}$ & $\begin{array}{l}2010 \\
2013\end{array}$ & 1 & 3 & 0 & 4 \\
\hline $\begin{array}{l}\text { A aprendizagem significativa e conhecimentos } \\
\text { prévios: investigando o currículo de Matemática, em } \\
\text { uma perspectiva construtivista }\end{array}$ & $\begin{array}{l}2011 \\
\text { Atual }\end{array}$ & 0 & 2 & 2 & 4 \\
\hline $\begin{array}{l}\text { Organização curricular e formação de professores } \\
\text { que ensinam Matemática em diferentes níveis e } \\
\text { modalidades de ensino }\end{array}$ & $\begin{array}{l}2011 \\
\text { Atual }\end{array}$ & 4 & 0 & 0 & 4 \\
\hline $\begin{array}{l}\text { Relações entre professores e materiais que } \\
\text { apresentam o currículo de Matemática: um campo } \\
\text { emergencial }\end{array}$ & $\begin{array}{l}2012 \\
\text { Atual }\end{array}$ & 5 & 4 & 1 & 10 \\
\hline $\begin{array}{l}\text { Pesquisas comparativas sobre organização e } \\
\text { desenvolvimento curricular na área de Educação } \\
\text { Matemática, em países da América Latina }\end{array}$ & $\begin{array}{l}2009 \\
\text { Atual }\end{array}$ & 6 & 0 & 0 & 6 \\
\hline \multicolumn{2}{|l|}{ TOTAL } & 25 & 29 & 35 & 89 \\
\hline
\end{tabular}

Fonte: Pires e Gonçalves (2015)

Além da produção científica apresentada (tabela 1), o grupo de pesquisa dispõe de outras produções (publicações em livros, artigos e anais) que julgamos representar certo pioneirismo na tomada de bases teóricas distintas para estudos curriculares realizados no âmbito da Educação Matemática; nesse contexto, apontamos a Educação Comparada como uma das perspectivas conceituais e epistemológicas norteadoras das investigações guiadas pelo grupo de pesquisa.

${ }^{2}$ Disponível em: <dgp.cnpq.br/dgp/espelhogrupo/7239683068499734>. Acesso em: 17 abr. 2016. 
A concepção inicial do projeto de pesquisa supramencionado parte de uma análise feita no Banco de Teses da Capes e em outras bases de dados em que se constatou uma carência de pesquisas comparativas relativas a currículos de Matemática no Brasil e em outros países, particularmente os latino-americanos, que considerassem as possíveis similaridades entre eles, ou seja, carência de investigações curriculares que identificassem e afirmassem, na área da Educação Matemática e subsidiados pela Educação Comparada, aspectos constituintes do currículo de Matemática desses países, tanto em termos de desafios a serem enfrentados como em relação a possíveis soluções encontradas que possam ser compartilhadas. Para tanto, foram estabelecidos quatro objetivos para a pesquisa: identificar aspectos comuns e especificidades dos currículos de Matemática em cada um desses países e as formas de organização; identificar os principais impactos da Educação Matemática na formulação de currículos prescritos; buscar dados que evidenciem a adesão ou a rejeição dos professores de Matemática às orientações curriculares prescritas nos documentos oficiais; buscar indícios referentes aos currículos que realmente se efetivem nas salas de aula (PIRES, 2013).

Tais objetivos nos levaram à formulação das seguintes questões norteadoras: Que Matemática está sendo proposta a ser ensinada a crianças e jovens de países latinoamericanos nesse início de milênio? Que pressupostos norteiam os documentos curriculares em países latino-americanos? Como se dá o processo de implementação curricular nesses países? (PIRES, 2013)

No âmbito do projeto de pesquisa foram defendidas as seguintes teses de doutorado na PUC/SP:

- Estudo comparativo sobre Brasil e Chile: tese de Dermeval Santos Cerqueira título: Um estudo comparativo entre Brasil e Chile sobre Educação Matemática e sua influência nos currículos de Matemática desses países; ano da defesa: 2012 (CERQUEIRA, 2012);

- Estudo comparativo sobre Brasil e Paraguai: tese de Marcelo de Oliveira Dias título: Educação Matemática e sua influência nos currículos prescritos e praticados: um estudo comparativo entre Brasil e Paraguai; ano da defesa: 2012 (DIAS, 2012);

- Estudo comparativo sobre Brasil e Argentina: tese de Emílio Celso Oliveira - título: Impactos da Educação Matemática nos currículos prescritos e praticados: estudo comparativo entre Brasil e Argentina; ano de defesa: 2013 (OLIVEIRA, 2013); 
- Estudo Comparativo sobre Brasil e Uruguai: tese de Luciane Santos Rosenbaum título: Estudo comparativo sobre a Educação Matemática presente em currículos: Brasil e Uruguai; ano de defesa: 2014 (ROSENBAUM, 2014);

- Estudo comparativo sobre Brasil e Peru: tese de Miguel Fortunato Athias - título: Currículos da Educação Básica do Peru e Brasil: prescritos e praticados (ATHIAS, 2015).

Vinculado ao projeto de pesquisa, encontra-se em processo de finalização um estudo doutoral sobre Brasil e México realizado por Marcelo Navarro da Silva.

Além dos mencionados estudos doutorais, foi realizado o estágio de pós-doutorado do Professor Dr. Harryson Júnio Lessa Gonçalves (Universidade Estadual Paulista "Júlio de Mesquita Filho" - Unesp), no Programa de Pós-Graduação em Educação Matemática da UFMS, sob a supervisão da coordenadora do projeto e financiado pelo CNPq. No pósdoutorado, o pesquisador elaborou uma meta-análise das teses produzidas no projeto visando a analisar a organização curricular da Matemática dos países, em específico do Ensino Médio, e identificou em suas recomendações/orientações os impactos de teorizações da Educação Matemática na elaboração de tais currículos.

\subsection{Alguns pressupostos teóricos - a Educação Comparada}

Neste tópico apresentaremos alguns dos pressupostos conceituais e epistemológicos que permearam a construção do referido projeto de pesquisa.

A Educação Comparada, segundo Mattheou (2012), surgiu com o estabelecimento de sistemas nacionais de educação, em um período em que disciplinas da área de humanidades dominavam o currículo escolar na Europa.

As primeiras pesquisas que tratavam de comparar os sistemas nacionais de ensino obtinham informações para que esses diferentes países copiassem as boas experiências uns dos outros, evitando-se, assim, erros. No século XIX, diversos países da Europa, os EUA e, inclusive, o Brasil promoveram viagens para a realização desses estudos a respeito da educação em outros países. Contudo, nos anos 1980 e 1990, a Educação Comparada sofreu perda de prestígio, em virtude das críticas às teorias de modernização, do capital humano, do desenvolvimento dependente, bem como dos próprios resultados alcançados por elas. Nesse contexto, seus métodos, sua validade científica, suas bases teóricas e mesmo suas finalidades foram questionados, sob a premissa de que seus resultados eram utilizados de modo abusivo para legitimar as ações reformadoras em nível nacional, em 
geral, vinculadas às orientações ou diretrizes dos organismos internacionais - como ONU, Unesco, FMI, Banco Mundial, OCDE (CARVALHO, 2013).

No Brasil, nos anos 1980, a Educação Comparada chegou a ser extinta de cursos superiores (graduação e pós-graduação) corroborando um quadro de enfraquecimento das bases epistemológicas da área. Nos anos 1990 ocorre uma revitalização dos estudos comparativos, inseridos em processos internacionais - reorganização da ordem mundial e dos processos de globalização, da desnacionalização da economia, do enfraquecimento do Estado-Nação e da influência das agências internacionais sobre as políticas nacionais de educação, evidenciando um crescente interesse pela realidade educacional de outros países. Assim, surge um processo de revalorização da Educação Comparada em nível internacional, acompanhado de críticas aos modos de interpretação e quadros de análise anteriores, abrindo novas perspectivas teórico-metodológicas e acentuando um contexto de economia globalizada em que se fortalecem processos avaliativos internacionais em larga escala justificados pela necessidade de garantias de padrões de qualidade da educação (CARVALHO, 2013).

A Educação Comparada necessita de novos caminhos e direcionamentos, tendo em vista seu desprestígio no meio acadêmico, necessitando de bases teóricas mais sólidas (NÓVOA, 2009). Para tanto, é preciso pensá-la em três novas frentes: (i) novos problemas - constituir os objetos de estudo em torno de um "vaivém" entre local e global, nomeadamente no que diz respeito ao trabalho realizado nas instituições educativas (currículo, administração escolar, professor, avaliação e demais); (ii) novos modelos de análise - que não tomem como referência unicamente dados estruturais, mas que sejam capazes de atribuir razão às práticas de diferentes atores (individuais, institucionais e políticos) e ao modo como elas reorganizam os espaços e os sentidos em níveis nacionais e internacionais; (iii) novas abordagens - baseando-se no aumento do repertório metodológico do trabalho comparativo (desde as análises macroeconômicas e políticas até as perspectivas etnográficas), e não no intuito de encontrar o "melhor" método.

Destacamos quatro finalidades da investigação em Educação Comparada (FERRER JULIÁ, 2002): (a) ilustrar as diferenças ou semelhanças entre os sistemas educacionais; (b) mostrar a importância dos fatores contextuais dos sistemas educativos como elementos explicativos de si mesmos; (c) estabelecer as possíveis influências dos sistemas educativos sobre determinados fatores contextuais; (d) contribuir para melhor compreensão do sistema educativo de um país mediante o conhecimento do sistema educativo de outros países. 
Pilz (2012), pensando os pressupostos epistemológicos da Educação Comparada, afirma que, para se efetivarem tais estudos comparados, o investigador necessita estabelecer critérios significativos ou que determinem as diferenças para que se possam comparar realidades distintas. Ou seja, o autor exemplifica que seria como comparar "maçãs com laranjas"; ele cita Hörner para argumentar que, "ao contrário da crença popular, as maçãs podem ser comparadas com laranjas ou peras, desde que haja um critério significativo para comparação (seu teor de sumo, por exemplo) ou um critério para determinar diferença, tal como o formato da fruta" (p. 563, tradução nossa). Assim, evidenciamos que o critério de análise da investigação torna-se basilar para a realização Educação Comparada.

A partir desse critério, Ferrer Juliá (2002) propõe que a investigação comparativa pode ser delineada a partir de seis fases: (1.ạ) Fase pré-descritiva - seleção, identificação e justificativa do problema; formulação de hipóteses; delimitação da investigação; (2.ạ) Fase descritiva - apresentam os dados contextuais, caracterizando o sistema educacional; (3.a Fase interpretativa - interpretação dos dados descritos na fase anterior, finalizando com uma síntese analítica com conclusões; (4.ạ) Fase de justaposição - confrontação dos dados produzidos nas fases anteriores; (5. $\left.{ }^{-}\right)$Fase comparativa - discussão das hipóteses a partir dos dados apresentados nas fases anteriores, bem como discussão das questões de pesquisa; (6.a ) Fase prospectiva - fase optativa que aponta as tendências em Educação nos países investigados.

A partir de estudos de vários autores, Pilz (2012) sintetiza as diversas fases de desenvolvimento metodológico do estudo comparativo em apenas quatro: (1..$^{a}$ ) Fase descritiva - observações e descrições; (2.. ${ }^{a}$ ) Fase explicativa - introduz interpretação, com o objetivo de explicar e compreender; (3. $\left.{ }^{a}\right)$ Fase de justaposição - primeira tentativa de comparação, oferecendo a constatação nacional definida no contexto dos critérios de comparação selecionados para avaliação e análise de lado a lado - isto permite, por exemplo, homólogos, análogos e diversos fenômenos a serem derivados, com possíveis hipóteses comparativas; (4.a ) Fase comparativa - as hipóteses comparativas são testadas usando a comparação sistemática, as relações entre os países são avaliadas por referência ao critério de comparação e conclusões podem ser tiradas para o assunto a ser pesquisado.

A partir dessas fases, o investigador em Educação Comparada deve mergulhar nas realidades sociais, econômicas, culturais, históricas, políticas e educacionais das nações investigadas e, a partir de critério(s) previamente estabelecido(s) (tônica central da 
Educação Comparada), analisa sua problemática investigativa, indo além de meras e fragmentadas descrições de realidades.

Assim sendo, centrado nos pressupostos anteriormente discutidos, foram delineados (e fundamentados) os estudos doutorais realizados no âmbito do projeto de pesquisa. Para tanto, os pesquisadores seguiram trajetórias similares nas suas teses: (i) levantamento de teses, particularmente no Banco de Teses da Capes e no sítio do Programa de PósGraduação Interunidades em Integração da América Latina (Prolam/USP); (ii) pesquisa documental com o objetivo de buscar informações preliminares sobre os currículos de Matemática prescritos pelos países pesquisados para os níveis correspondentes à Educação Básica brasileira, além de dados sobre legislação, organização dos sistemas educativos e ações empreendidas pelos Ministérios de Educação, no sentido de propor orientações curriculares e implementá-las, ao longo da década de 1990 e até o momento atual; (iii) além de buscas on-line, os doutorandos, nessa fase, fizeram seus primeiros contatos com professores/pesquisadores de outros países, com a colaboração muito especial da Professora Norma Cotic, da Argentina, dos Professores Ismezia Gusman e Fidel Oteíza do Chile, das Professoras Avelina Demestri e Nelida Centurion do Paraguai. Esses pesquisadores enviaram documentos e contribuíram para a organização da visita que seria posteriormente realizada pelos doutorandos aos países que estavam pesquisando; (iv) ao mesmo tempo em que desenvolviam essas ações, os doutorandos se dedicaram aos estudos teóricos referentes a estudos comparados, concepções de currículos, tendências da Educação Matemática, com intuito de analisar os possíveis impactos dessas teorizações nos currículos de Matemática; (v) Seguiu-se a fase de preparação de instrumentos para a coleta de dados tanto no Brasil como nos outros países, procurando-se identificar diferentes atores do processo de organização e desenvolvimento curricular, elaboradores de currículos prescritos, coordenadores, diretores e professores responsáveis pelos currículos moldados e colocados em ação nas salas de aula. Novamente, foi fundamental a colaboração dos pesquisadores anteriormente citados que ajudaram a colocar os doutorandos em contato com os entrevistados e agendar encontros e visitas a escolas e a outras instituições educacionais (PIRES, 2013).

\subsection{Alguns desafios}

A partir de meta-análise dos estudos doutorais, alguns desafios se revelaram para investigações em Educação Comparada. O primeiro se refere à natureza intercultural desse tipo de pesquisa. Ao se realizar o planejamento da pesquisa, o investigador deve prever 
desenhos metodológicos (e seus diversos instrumentos) que façam sentido em países diferentes e que tenham aceitável validade nos contextos. Para isso, recomendamos o envolvimento de pesquisadores das diversas nações estudadas para melhor interpretação "intercultural".

Outro desafio a ser observado metodologicamente em Educação Comparada é a confiabilidade na coleta de dados, tendo o cuidado para que sejam conduzidos trabalhos de campo que sigam normas semelhantes em contextos diversos. Para superar esse desafio, pesquisadores devem utilizar roteiros de pesquisas semelhantes e em versões idiomáticas equivalentes. Cabe recomendar que os pesquisadores da Educação Comparada tenham domínio dos idiomas dos países investigados visto a necessidade de análise e interpretação direta dos dados pelos pesquisadores envolvidos.

Outro desafio a ser observado em Educação Comparada pode ser, a partir do uso de instrumentos semelhantes, notar que nas diferentes realidades esses instrumentos estejam carregados de significados distintos, acessando fenômenos diversificados. Nesse caso, o pesquisador deve estar atento às necessidades de ajustes ou adaptações do(s) instrumento(s) de pesquisa.

\subsection{Algumas análises}

Neste tópico apresentaremos um panorama da estrutura curricular dos países investigados (estudos concluídos: Brasil-Argentina, Brasil-Chile, Brasil-Paraguai, BrasilPeru e Brasil-Uruguai) pelo projeto "Pesquisas comparativas sobre organização e desenvolvimento curricular na área de Educação Matemática, em países da América Latina". Ressaltamos que o detalhamento de tais estudos pode ser apreciado nas respectivas teses de doutorado já defendidas no Programa de Estudos Pós-Graduados em Educação Matemática da PUC/SP: Cerqueira (2012), Dias (2012), Oliveira (2013), Rosenbaum (2014) e Athias (2015) - disponíveis no portal do Programa de Estudos PósGraduados em Educação Matemática da PUC/SP. Salientamos ainda que nas referidas teses são explicitadas as condicionantes sociais, políticas, históricas, econômicas e pedagógicas dos países investigados que subsidiam a compreensão totalitária da estrutura curricular dos sistemas educacionais investigados. Logo, optamos por realizar um recorte global da estrutura curricular oficial desses países, a partir das referidas teses, apenas para brevemente ilustrarmos alguns resultados. 
Todos os países tiveram suas leis magnas da educação constituídas a partir de um contexto de abertura política perante os regimes militares enfrentados por países latinoamericanos em estado de redemocratização. Assim, temos as seguintes leis de educação: Argentina - Lei da Educação Nacional (Lei n. ำ 24.195/1993); Brasil - Lei de Diretrizes e Bases da Educação Nacional (Lei n. 9.394/1996); Chile - Lei Geral da Educação (Lei n.ำ 20.370/2009); Paraguai - Lei Geral da Educação (Lei n. 1.264/1998); Uruguai - Lei Geral da Educação (Lei n.ำ 18.437/2008); Peru (Lei n.ำ 28.044/2003).

A partir das leis magnas de educação supramencionadas, elaboramos um quadro sintético comparativo (figura 1) da estrutura educacional dos países investigados com 0 intuito de facilitar a compreensão das peculiaridades e similaridades desses sistemas educacionais. No quadro, apresentamos apenas os níveis de ensino equivalentes à Educação Básica brasileira, excluindo as diversas modalidades de ensino, bem como aspectos comparativos relativos à Educação Superior.

Figura 1: Quadro comparativo dos sistemas educacionais (Argentina, Brasil, Chile,

Paraguai, Peru e Uruguai)

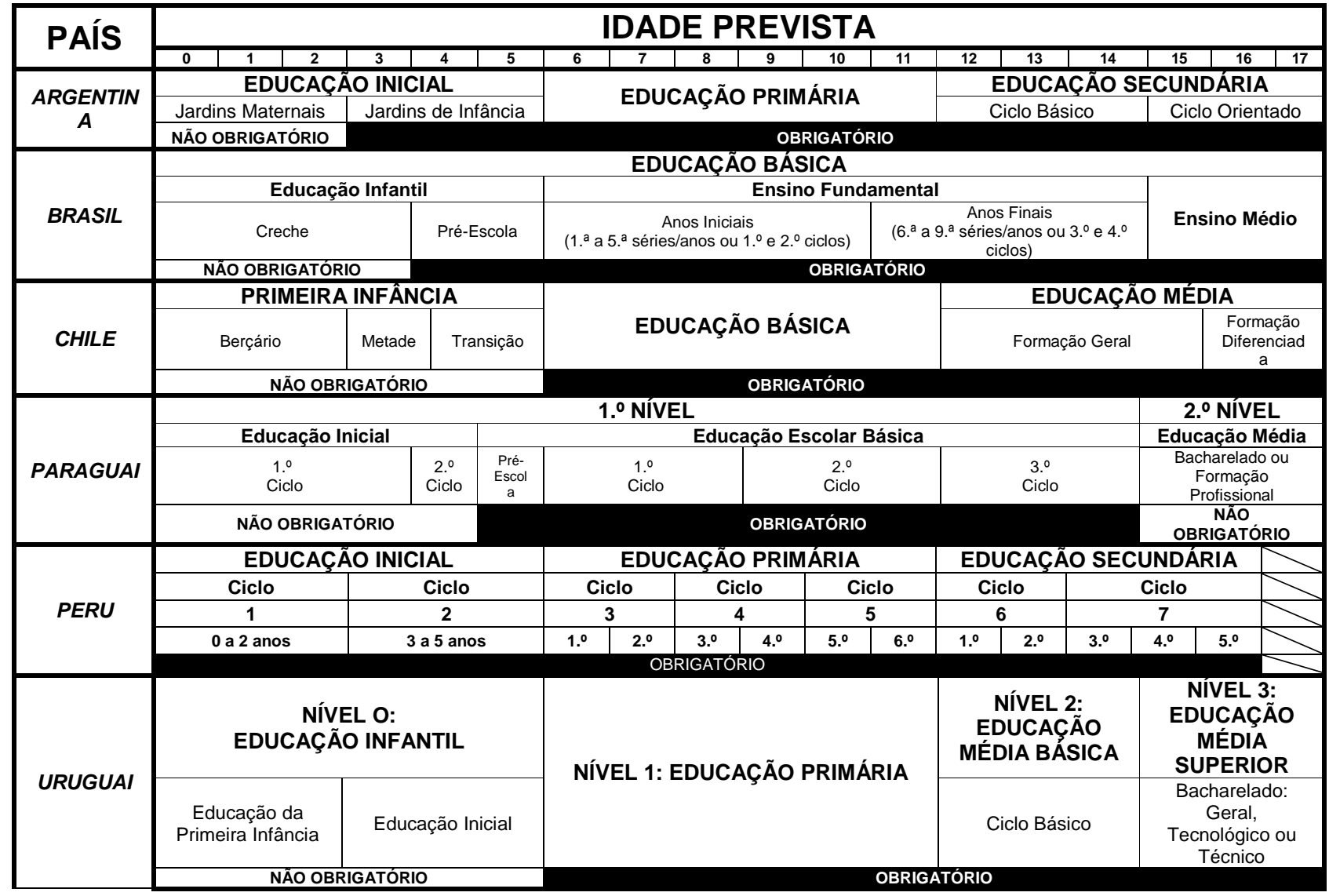

Fonte: Autores 
O estudo comparativo sobre Brasil e Uruguai revelou a influência das teorias curriculares críticas com a preocupação em um currículo "acessível", "rico" e "enculturador", a fim de se empenhar em superar as marcas das injustiças e desigualdades sociais, em especial, nas duas nações com a democratização dos anos 1980 após décadas de regime militar. Para Rosenbaum (2014), o reconhecimento do papel do currículo na formação da sociedade que se espera, com a preocupação de atender aos interesses sociais, é característica das prescrições curriculares dos países pesquisados. O ciclo correspondente no Uruguai, denominado Educação Primária, tem a extensão de seis anos. Os anos finais do Ensino Fundamental no Brasil com quatro anos, por sua vez, têm o correspondente no Uruguai, a Educação Média Básica ou Ciclo Básico com três anos de extensão. Finalmente, o Ensino Médio no Brasil, com três anos de duração, tem como equivalente no Uruguai a Educação Média Superior, denominado bacharelado, com a mesma extensão, contudo com maior flexibilização curricular.

Rosenbaum (2014) acrescenta que o bacharelado uruguaio sofreu uma mudança no ano de 2006 na tentativa de vencer problemas semelhantes aos brasileiros no que tange ao número de reprovações, evasão e abandono dos bancos escolares nessa etapa de ensino. O primeiro ano do bacharelado apresenta uma formação comum a todos os estudantes uruguaios; no segundo ano, são oferecidas quatro opções de trajetórias formativas aos alunos, e no último ano as opções diversificam-se em sete opções - uma flexibilização curricular baseada na preocupação de atender a diversidade dos alunos. Nos trabalhos de Cerqueira (2012), Oliveira (2013) e Athias (2015) também se percebem alternativas de flexibilização curricular no âmbito da educação secundária chilena, argentina e peruana.

O estudo de Cerqueira (2012) revelou que no Chile os profissionais de ensino conhecem o currículo oficial prescritos; no entanto, no Brasil, tal fato não se assemelha por não haver clareza na definição pelo Ministério de Educação (MEC) do documento prescrito oficial em que os professores devem se apoiar. Em geral, no Brasil, os sistemas de ensino se baseiam nos Parâmetros Curriculares Nacionais (PCN).

A investigação comparativa sobre Brasil e Paraguai (DIAS, 2012) evidenciou que os objetivos do Ensino Médio nos países investigados apresentam-se como ampliação daqueles colocados ao Ensino Fundamental, na perspectiva de que o estudante se insira no mundo do trabalho e tenha autonomia para continuar os estudos em nível superior. As concepções de escola e currículo, tal como os currículos prescritos em ambos os países investigados, demonstraram, no que diz respeito às finalidades para a Educação, em 
particular da Educação Matemática, que há necessidade de enfatizar o pleno exercício da cidadania. Nesse sentido, apontam o conhecimento específico matemático como ferramenta sublimar e indispensável para o desenvolvimento de capacidades e competências inerentes ao aspecto profissional, científico e tecnológico.

Oliveira (2013) apresenta indicadores que comprovam uma descontinuidade da escolarização básica na Argentina e no Brasil, visto que os alunos que iniciam os estudos não conseguem completar o percurso formativo da educação secundária em virtude do alto índice de evasão ou repetência. Nos últimos anos, os dois países procuraram, por meio de algumas iniciativas, entre elas mudanças curriculares que repensassem o Ensino Médio, uma forma de garantir o acesso e a permanência dos alunos na escola.

No Peru, conforme Athias (2015), o currículo fundamenta-se nos seguintes princípios: igualdade, inclusão, ética, multiculturalismo, democracia, consciência ambiental, criatividade e inovação. Para o autor, a Educação Básica Regular peruana possui como característica assegurar a evolução física, afetiva e cognitiva das crianças e jovens desde seu nascimento.

Em relação ao currículo de Matemática peruano, Athias (2015) afirma que o currículo apresenta como característica a densidade dos conteúdos; todavia, suas diretrizes sugerem "flexibilidade" na aplicação desses conteúdos, deixando a escola e o professor livres para adaptá-lo, de acordo com suas necessidades. Tal situação se difere do Brasil, onde não existem currículos oficiais estabelecidos, apenas parâmetros curriculares.

Os seguintes pressupostos teórico-metodológicos consubstanciam os currículos de Matemática dos países investigados: resolução de problemas como eixo metodológico; uso de situações contextualizadas e desafiadoras para os alunos; ênfase no papel do erro no processo de aprendizagem; uso de tecnologias (calculadoras, softwares computacionais etc.); abordagens interdisciplinares, modelagem e etnomatemática; uso de jogos e caráter lúdico das atividades matemáticas; recurso à história da Matemática (PIRES, 2013). Pressupostos teórico-metodológicos fundados na didática francesa também foram observados nos currículos: situações didáticas, contrato didático, obstáculos, entre outros (PIRES; GONÇALVES, 2012).

Nas figuras 2 e 3 são apresentados dois quadros com os blocos de conteúdos matemáticos dos países investigados, observando-se similaridades na seleção e organização de conteúdos. 
Figura 2: Blocos de conteúdos dos níveis equivalentes ao Ensino Fundamental brasileiro

\begin{tabular}{|c|c|c|c|c|c|c|}
\hline & ARGENTINA & BRASIL & ChILE & PARAGUAI & PERU & URUGUAI \\
\hline $\begin{array}{c}\text { ENSINO } \\
\text { FUNDAMENT } \\
\text { AL }\end{array}$ & $\begin{array}{c}\text { Número } \\
\text { Operação Linguagem } \\
\text { Gráfica e Algébrica } \\
\text { Noções Geométricas } \\
\text { Medidas } \\
\text { Noções de Estatística e } \\
\text { Probabilidade } \\
\text { Conteúdos } \\
\text { Procedimentais } \\
\text { Conteúdos Atitudinais }\end{array}$ & $\begin{array}{c}\text { Números e } \\
\text { Operações } \\
\text { Espaço e } \\
\text { Forma } \\
\text { Grandezas e } \\
\text { Medidas } \\
\text { Tratamento da } \\
\text { Informação }\end{array}$ & $\begin{array}{c}\text { Números e } \\
\text { Operações } \\
\text { Padrões } \\
\text { Algébricos e } \\
\text { Relações } \\
\text { Geométricas } \\
\text { Medidas e } \\
\text { Dados }\end{array}$ & $\begin{array}{l}\text { Números e } \\
\text { Operações } \\
\text { Geometria e } \\
\text { Medida } \\
\text { Operações e } \\
\text { Expressões } \\
\text { Algébricas } \\
\text { Geometria e } \\
\text { Medidas } \\
\text { Os dados e a } \\
\text { Estatística }\end{array}$ & $\begin{array}{l}\text { Números, } \\
\text { Relações } \\
\text { e } \\
\text { Operações } \\
\text { Geometria } \\
\text { e Medidas } \\
\text { Estatística }\end{array}$ & $\begin{array}{c}\text { Números } \\
\text { Operações } \\
\text { Magnitudes e } \\
\text { Medidas } \\
\text { Estatística e } \\
\text { Probabilidade } \\
\text { Álgebra } \\
\text { Geometria }\end{array}$ \\
\hline
\end{tabular}

Fonte: Autores

Figura 3: Blocos de conteúdos dos níveis equivalentes ao Ensino Médio brasileiro

\begin{tabular}{|c|c|c|c|c|c|c|}
\hline & ARGENTINA & BRASIL & CHILE & PARAGUAI & PERU & URUGUAI \\
\hline $\begin{array}{l}\text { ENSINO } \\
\text { MÉDIO }\end{array}$ & $\begin{array}{l}\text { Números e } \\
\text { Funções } \\
\text { Álgebra e } \\
\text { Geometria } \\
\text { Estatística e } \\
\text { Probabilidade } \\
\text { Conteúdos } \\
\text { Procedimentais } \\
\text { Conteúdos } \\
\text { Atitudinais }\end{array}$ & $\begin{array}{l}\text { Álgebra: Números } \\
\text { e Funções: } \\
\text { Variação de } \\
\text { Grandezas; } \\
\text { Trigonometria } \\
\text { Geometria e } \\
\text { Medidas: } \\
\text { Geometria Plana; } \\
\text { Geometria } \\
\text { Espacial; Métrica; } \\
\text { Geometria } \\
\text { Analítica } \\
\text { Análise de Dados: } \\
\text { Estatística; } \\
\text { Contagem; } \\
\text { Probabilidade }\end{array}$ & $\begin{array}{c}\text { Números } \\
\text { Álgebra e } \\
\text { Funções } \\
\text { Geometria } \\
\text { Dados e Azar } \\
\text { Álgebra }\end{array}$ & $\begin{array}{c}\text { Álgebra } \\
\text { Trigonometria } \\
\text { Geometria } \\
\text { Analítica } \\
\text { Cálculo } \\
\text { Infinitesimal } \\
\text { Estatística e } \\
\text { Probabilidade }\end{array}$ & $\begin{array}{l}\text { Números, } \\
\text { Relações e } \\
\text { Funções } \\
\text { Geometria e } \\
\text { Medidas } \\
\text { Estatística e } \\
\text { Probabilidade }\end{array}$ & $\begin{array}{c}\text { Álgebra } \\
\text { Geometria } \\
\text { Estatística } \\
\text { Probabilidade } \\
\text { Funções } \\
\text { Números }\end{array}$ \\
\hline
\end{tabular}

Fonte: Autores

A seleção dos conteúdos produz uma longa lista de tópicos para cada etapa da escolaridade, evidenciando uma necessidade de questionar se esse não é um problema da Educação Matemática a ser investigado, qual seja o excesso de conteúdos que se propõem a trabalhar, em choque com o tempo didático disponível.

Ressaltamos a ausência, nos currículos prescritos dos países investigados, dos temas Conjuntos e Estruturas Algébricas - que caracterizaram os currículos no período de influência da Matemática Moderna - e a inclusão dos assuntos Estatística, Combinatória e Probabilidade desde os anos iniciais da escolaridade (PIRES, 2013b). 


\subsection{Algumas perspectivas}

A partir da meta-análise das teses produzidas no âmbito do projeto "Pesquisas comparativas sobre organização e desenvolvimento curricular na área de Educação Matemática, em países da América Latina", trazemos à tona a dimensão cultural como central para a Educação Comparada. Nesse sentido, a discussão referente à diversidade cultural torna-se basilar na condução de investigações curriculares em Educação Comparada.

A diversidade tem se tornado tônica central nas discussões atuais em razão da emergência significativa dos pluralismos étnicos, comportamentais e artigos de consumo, nacionalismos etc., assim podemos entender a diversidade cultural como aquela que diz respeito às manifestações plurais de grupos e sociedades em suas práticas culturais. A diversidade não pode ser pensada, segundo Gomes (2003), somente a partir de elementos externos, mas também do tratamento cultural e político dado a ela e que pode ser constituído de duas formas: (a) as diferenças são construídas culturalmente, tornando-se, então, empiricamente observáveis; (b) as diferenças também são construídas ao longo do processo histórico, nas relações sociais e nas relações de poder. Muitas vezes, os grupos humanos tornam o outro diferente para fazê-lo inimigo, para melhor dominá-lo.

Assim, para a autora, a diversidade cultural vai além do mero reconhecimento do outro, mas sim estabelece uma relação entre o "eu" e o "outro" - cerne da discussão da diversidade. Ou seja, romper com a perspectiva de entender semelhanças e diferenças a partir de comparações centradas em padrões e normas vigentes em nosso grupo ou próximos da nossa visão de mundo. Nesse sentido, a discussão de diversidade cultural vai além da análise de um determinado comportamento ou de uma resposta individual. Ela precisa abarcar a dimensão política, visto que ela permeia padrões e valores que regulam as relações.

Nesse contexto, conforme Urquiza, Pereira e Prado (2015), um elemento fundamental para nossa reflexão é a relação de alteridade: relação de confronto que a diferença estabelece entre ego (eu) e alter (outro). Tal relação apresenta-se com fonte de julgamento e decisões sobre o outro, por isso torna-se problemática, uma vez que o diferente existe independentemente de autorização, permissão e tolerância, tornando-se zona de tensão. Assim, "o outro, o externo a mim, ao ser diferente, torna-se um problema, pois leva a confrontar a própria identidade do 'eu'” (URQUIZA; PEREIRA; PRADO, 2015, p. 8). 
Conforme os autores citados, o problema da diferença é reduzir a uma questão de pertencimento, ou seja, "como o outro não pertence ao nosso grupo, à nossa cultura, o problema é ele - o outro" (URQUIZA; PEREIRA; PRADO, 2015, p. 9). A dificuldade de pensarmos o contrário e, assim, nos concebermos como o centro da razão gera um comportamento etnocêntrico - visão de mundo em que tomamos nosso próprio grupo como referência e, consequentemente, o centro de tudo.

Por outro lado, a diversidade potencializa a humanização, ou seja, "abre possibilidades de novos conhecimentos, de aprendizados, de construção de formas pacíficas e colaborativas de viver" (URQUIZA; PEREIRA; PRADO, 2015, p. 9).

Assim, os conceitos de diversidade e diferença se fazem urgentes à Educação Comparada, consubstanciando-se na Antropologia. A diversidade traz consigo o reconhecimento de pluralidade de culturas presentes nas sociedades, com sua multiplicidade de significados, exigindo postura política e ética de respeito, visando a uma convivência democrática. A diferença apresenta-se como processo de constituição e hierarquização desses significados múltiplos. Segundo Laraia (2008), o ponto de partida é, por um lado, a constatação da unidade genética (biológica) dos seres humanos e, por outro lado, a imensa diversidade cultural produzida por esses mesmos seres humanos.

Portanto, afirmar aspectos identitários a partir das ancestralidades, perpassando pela importância da valorização dos etnossaberes, possibilita estabelecer fontes interculturais, construídas, principalmente, pela Antropologia, e que nos possibilita ainda compreender e valorizar a relação com o outro a partir de um olhar para a diversidade, que é inerente às nações investigadas (plurais e diversas). Torna-se fundamental lidar com a diversidade a partir do relacionamento com o diferente - outras formas de olhar o mundo e a natureza -, fazendo com que a interculturalidade promova possibilidades de convivências centradas em compreensões e trocas de significados. Para tanto, deve haver um questionamento dos "fantasmas" construídos que subjugam as diversas culturas, por vezes constituídas a partir de uma colonialidade eurocêntrica. Problematizar tais questões nas investigações curriculares em Educação Matemática desenvolvidas em Educação Comparada, a partir de novos olhares, configura-se atitude respeitosa dessa diversidade em especial latino-americana.

Outra perspectiva que apresentamos como teórica para a Educação Comparada é o referencial teórico pós-colonialista. 
O discurso pós-colonialista caracteriza-se como uma perspectiva teórica que agrega teorias fundadas na Filosofia, Literatura e Ciência Política cujo norte é uma reação contra o legado colonial, ou seja, visa a "analisar o complexo das relações de poder entre as diferentes nações que compõem a herança econômica, política e cultural da conquista colonial europeia tal como se configura no presente momento chamado, é claro, de pós-colonial" (SILVA, 2007, p. 125).

Quijano (2000) aponta que a colonialidade é um pressuposto específico e constitutivo do padrão mundial de poder capitalista; subsidia-se na imposição de uma classificação étnico-racial da população do mundo como basilar do padrão de poder e opera em cada um dos planos, âmbitos e dimensões materiais e subjetivas, da existência social cotidiana e da escala social. $\mathrm{O}$ autor acrescenta ainda que tal colonialidade se originaliza e se mundializa a partir da América Latina.

Assim, corroboramos as ideias de Calderoni (2016), de que, apesar da independência das ex-colônias e da constituição dessas nações, diversos fatores sociais e políticos não garantiram a descolonização, mantendo-se a colonialidade por meio político, cultural, epistêmico, jurídico e administrativo. Assim, com o intuito de contribuir com tal processo de descolonialidade, apresentamos o presente artigo defendendo a Educação Comparada como perspectiva teórica em estudos curriculares latino-americano no âmbito da Educação Matemática.

\section{Considerações}

Assentamos nossas reflexões no presente artigo no pressuposto de que a Educação Comparada vai além de meras comparações de sistemas de ensino, por vezes incomparáveis. A partir disso, e de uma meta-análise de estudos que propõem a dimensão comparativa no âmbito da Educação Matemática, observamos estar ainda muito incipiente a incorporação da diversidade cultural como basilar na condução de estudos comparativos. Propomos, assim, a adoção de elementos teóricos que ultrapassem uma descrição normativa dos currículos estudados e que incorporem a compreensão dos aspectos culturais constitutivos dos currículos de Matemática das nações investigadas, a partir de imersões em realidades distintas. Acreditamos que tal perspectiva se torna urgente para possibilitar uma nova ótica (e compreensão) de problemas comuns enfrentados pelos sistemas de ensino estudados. 
Nessa ocasião, ressaltamos a Educação Comparada como perspectiva que contribui com o processo de integração latino-americana, principalmente tendo o pós-colonialismo como pressuposto teórico.

\section{Referências}

ATHIAS, Miguel Fortunato. Currículos da educação básica do Peru e Brasil: prescritos e praticados. 2015. 240 f. Tese (Doutorado em Educação Matemática) - Pontifícia Universidade Católica de São Paulo, São Paulo.

BRASIL. Lei $n^{\circ}$ 9394, de 20 de dezembro de 1996. Lei de diretrizes e bases da educação nacional. p. 1-27. Disponível em: <http://www.planalto.gov.br/ccivil_03/leis/19394.htm>. Acesso em: 29 jul. 2017.

BRASIL. Lei no 13.005, de 25 de junho de 2014. Aprova o Plano Nacional de Educação - PNE e dá outras providências. p. 1-15. Disponível em: <http://www.planalto.gov.br/ccivil_03/_ato20112014/2014/lei/13005.htm>. Acesso em: 29 jul. 2017.

CALDERONI, Valéria Aparecida Mendonça de Oliveira. Desconstruindo preconceitos sobre os povos indígenas: módulo $\mathrm{V}$ do curso de especialização em antropologia e história dos povos indígenas. Campo Grande: UFMS, 2016.

CARVALHO, Elma Júlia Gonçalves de. Estudos comparados: repensando sua relevância para a educação. Revista HISTEDBR On-line, Campinas, n. 52, p. 416-435, set. 2013. Disponível em: <https://goo.gl/K0x4aM>. Acesso em: 5 jul. 2015.

CERQUEIRA, Dermeval Santos. Um estudo comparativo entre Brasil e Chile sobre educação matemática e sua influência nos currículos de matemática desses países. 2012. 254 f. Tese (Doutorado em Educação Matemática) - Pontifícia Universidade Católica de São Paulo, São Paulo.

DIAS, Marcelo de Oliveira. Educação matemática e sua influência nos currículos prescritos e praticados: um estudo comparativo entre Brasil e Paraguai. 2012. $316 \mathrm{f}$. Tese (Doutorado em Educação Matemática) - Pontifícia Universidade Católica de São Paulo, São Paulo.

FERRER JULIÁ, Ferrán. La educación comparada actual. Barcelona: Ariel, 2002.

GOMES, NIIma Lino. Educação e diversidade étnico-racial. In: MEC. Diversidade na educação: reflexões e experiências. Brasília: MEC, 2003.

KAZAMIAS, Andreas M. Educação comparada: uma reflexão histórica. In: ; COWEN, Robert; ULTERHALTER, Elaine (Org.). Educação comparada: panorama internacional e perspectivas. Brasília: Unesco, Capes, 2012. v. 1, p. 173-193. Disponível em: <http://goo.gl/xEHSyw>. Acesso em: 5 jul. 2015.

LARAIA, Roque de B. Cultura: um conceito antropológico. Rio de Janeiro: Jorge Zahar, 2008.

MATTHEOU, Dimitris. O paradigma científico na educação comparada. In: COWEN, Robert; KAZAMIAS, Andreas M.; ULTERHALTER, Elaine (Org.). Educação comparada: panorama internacional e perspectivas. Brasília: Unesco, Capes, 2012. v. 1, p. 81-95. Disponível em: <http://goo.gl/xEHSyw>. Acesso em: 5 jul. 2015. 
NEWCOMB, Robert Patrick. Nossa and nuestra America: inter-American dialogues. West Lafayette: Purdue University Press, 2012.

NÓVOA, António. Modelo de análise de educação comparada: o campo e o mapa. In: SOUZA, Donaldo Bello de; MARTINS, Silvia Alicia (Org.). Educação comparada: rotas de além-mar. São Paulo: Xamã, 2009. p. 23-62.

OLIVEIRA, Emílio Celso. Impactos da educação matemática nos currículos prescritos e praticados: estudo comparativo entre Brasil e Argentina. 2013. 283 f. Tese (Doutorado em Educação Matemática) - Pontifícia Universidade Católica de São Paulo, São Paulo.

ORGANIZAÇÃO DAS NAÇÕES UNIDAS PARA A EDUCAÇÃO, A CIÊNCIA E A CULTURA (UNESCO). Declaração Mundial de Educação para Todos. Jomtien: Unesco, 1990. Disponível em: <http://unesdoc.unesco.org/images/0008/000862/086291 por.pdf>. Acesso em: 23 maio 2016.

PHILLIPS, David. Aspectos da transferência educacional. In: COWEN, Robert; KAZAMIAS, Andreas M.; ULTERHALTER, Elaine (Org.). Educação comparada: panorama internacional e perspectivas. Brasília: Unesco, Capes, 2012. v. 2, p. 497-515. Disponível em: <http://goo.gl/xEHSyw>. Acesso em: 5 jul. 2015.

PILZ, Matthias. International comparative research into vocational training: methods and approaches. In: Springer, 2012. (Ed.). The future of vocational education and training in a changing world, p. 561-588.

PIRES, Célia Maria Carolino. Pesquisas comparativas sobre organização e desenvolvimento curricular na área de Educação Matemática, em países da América Latina. Educação matemática pesquisa, São Paulo, v. 15, n. 2, p. 513-542, maio-ago. 2013. Quadrimestral.

PIRES, Célia Maria Carolino; GONÇALVES, Harryson Júnio Lessa. Aspectos conceituais e epistemológicos da educação comparada presentes no projeto "Pesquisas comparativas sobre organização e desenvolvimento curricular na área de educação matemática, em países da América Latina". Perspectivas da Educação Matemática, Campo Grande, v. 8, n. 18, p. 396-414, set.-dez. 2015. Quadrimestral.

QUIJANO, Aníbal. Colonialidad del poder y clasificación social. Journal of world-systems research, v. 6, n. 2, p. 342-386, 2000.

ROSENBAUM, Luciane Santos. Estudo comparativo sobre a educação matemática presente em currículos: Brasil e Uruguai. 2014. Tese (Doutorado em Educação Matemática) - Pontifícia Universidade Católica de São Paulo, São Paulo.

SILVA, Tomaz Tadeu. Documentos de identidade: uma introdução às teorias do currículo. Belo Horizonte: Autêntica, 2007.

URQUIZA, Antônio Hilário Aguilera; PEREIRA, Levi Marques; PRADO, José Henrique. Antropologia indígena: $2 .{ }^{\circ}$ módulo do curso de especialização em antropologia e história dos povos indígenas. Campo Grande: UFMS, 2015.

Submissão: $12 / 12 / 2016$

Aceite: 18/08/2017 